\title{
Verbal discrimination learning theory and differential eyelid conditioning to related words at three interstimulus intervals
}

\author{
LOUISE C. PERRY \\ University of Queensland, St. Luica, Queensland, Australia 4067
}

\begin{abstract}
Two experiments examined the relevance of frequency theory and feature analysis models of verbal discrimination learning (VDL) for differential eyelid conditioning to related words. The single reinforced and nonreinforced stimuli were: (a) high associates, (b) homonyms, (c) members of the same taxonomic class, (d) unrelated nouns, or (e) unrelated noun and adjective or verb items. Experiment I examined these five types of relatedness at 1000 -msec and 1400 -msec interstimulus intervals (ISI), while Experiment II tested ISIs of $1000 \mathrm{msec}$ and $600 \mathrm{msec}$. Conditioned discrimination was generally poorer at the 600-msec ISI, but neither VDL model's relatedness interference predictions were fully confirmed. Contrary to frequency theory, associates were no more difficult to discriminate than unrelated words. The feature analysis model was partially supported, in that taxonomic but not homonymic relatedness produced some interference at the 600 -msec ISI. Possible process differences between verbal recognition learning and differential conditioning which may account for these results were discussed.
\end{abstract}

The present research examined the relevance of recognition learning theory for human classical conditioning. Specifically, differential conditioning to verbal conditioned stimuli (CSs) was viewed as an analog to verbal discrimination learning (VDL), and the predictions of two alternative VDL theories were contrasted within the context of differential eyelid conditioning to related verbal discriminanda. The positive stimulus word (CS+), reinforced by occurrence of the unconditioned stimulus (US), and the negative or nonreinforced word (CS-) were either high normative associates, members of the same taxonomic category, homonyms, unrelated nouns, or unrelated noun-nonnoun (adjective or verb) combinations.

According to frequency theory (Ekstrand, Wallace, \& Underwood, 1966), associative relatedness between correct (R) and incorrect (W) items interferes with VDL because the occurrence of the $R$ and $W$ items as implicit associative responses (IARs) retards the development of discriminable subjective R-W frequency differences. The analogous prediction in the present situation is that differential conditioning should be detrimentally affected by associative relatedness, but not by homonymic or taxonomic relatedness, assuming

This research was submitted in partial fulfillment of the requirements for the $\mathrm{PhD}$ degree at the University of WisconsinMadison. It was supported in part by a Public Health Service predoctoral fellowship and by Research Grant MH0692 to David A. Grant. The author wishes to express sincere thanks and appreciation to Professor Grant for his advice, encouragement, and support throughout the project. Reprint requests should be sent to Louise C. Perry, Department of Psychology, University of Queensland, Brisbane, Queensland, Australia 4067. R. W. Schulz sponsors this paper and takes full editorial responsibility for its contents. that the latter do not elicit such IARs to any extent. The feature-tagging VDL hypothesis (e.g., Kausler, $1974 a, b)$ instead assumes that the featural components of an $\mathrm{R}$ item are tagged differently from those of its paired $\mathrm{W}$ item, and it is this disparity in tagging which serves to identify the correct item. The probability of wrongly identifying a W item as correct is assumed to depend on the extent to which $\mathrm{R}$ and $\mathrm{W}$ items share sensory and semantic features. Hence, VDL interference should result from the use of homonyms, which have sensory features in common, as well as from conceptually related words with overlapping semantic attributes, but not from high associates (if distinct in their sensory and semantic features). The analogous expectation here, therefore, is that homonymic and taxonomic relatedness, but not associative relatedness, should interfere with differential conditioning.

Two different control groups were included because of the confounding of grammatical class differences with type of relatedness, i.e., the CS+ and $\mathrm{CS}-$ were both nouns in the taxonomic condition, while the homonym and associative discriminanda were all nounnonnoun (adjective or verb) combinations. Because differential stimuli which are nouns are likely to be higher in imagery than nonnoun CSs, and there is evidence to suggest that imagery may aid differential conditioning (Perry, Grant, \& Schwartz, Note 1), the most appropriate control comparisons are an unrelated noun group for taxonomic class words and an unrelated noun-nonnoun group for associates and homonyms.

Finally, in view of VDL data (Eckert \& Kanak, 1974; McCarthy, 1973) suggesting that relatedness effects may depend upon the temporal parameters of the 
situation, the interstimulus interval (ISI) between CS and US onset was also manipulated. Experiment I examined the five types of relatedness at ISIs of 1000 and $1400 \mathrm{msec}$, while Experiment II tested ISIs of 1000 and $600 \mathrm{msec}$.

\section{EXPERIMENT I}

\section{Method}

Experimental Design and Apparatus. A 5 by 2 betweensubjects factorial design was employed: type of relatedness between the CS+ and CS- (associative, taxonomic, homonymic, unrelated noun, or unrelated noun-nonnoun stimuli) by ISI (1000 or $1400 \mathrm{msec})$. The equipment was standard eyelid conditioning apparatus similar to that used by Cerekwicki et al. (1968). The word stimuli were back-projected onto a $45 \times 301 / 2 \mathrm{~cm}$ ground glass screen at the rear of the subject's soundproof chamber. The projected word length subtended a visual angle of $11.3 \mathrm{deg}$, the letter height $2.9 \mathrm{deg}$, and the stroke width $.5 \mathrm{deg}$.

The CS duration was either 1200 or $1600 \mathrm{msec}$ for the $1000 \mathrm{msec}$ and $1400 \mathrm{msec}$ ISIs, respectively. The US was a 200 -msec $13,789.52 \mathrm{~N} / \mathrm{m}^{2}$ (2 psi) puff of nitrogen which terminated with the offset of the CSt. Intertrial intervals were 16 , 20 , or $24 \sec (M=20 \mathrm{sec})$.

Stimulus Materials. The CSs were all common (ThorndikeLorge A or AA) four-letter words. One response word from a given category in the Cohen, Bousfield, and Whitmarsh norms (1957) was used as a CS for both the associative and taxonomic conditions, while the other CS was either a strong associate (Shapiro \& Palermo, 1968) or another response word from the same category. In all conditions three different but comparable CS+, CS - sets were each given to a third of the subjects. The unrelated word sets were formed by pairing the words which occurred in both the associative and taxonomic conditions with homonym set items. The word DOOR, for example, was used with OPEN, WALL, BEAR, or BARE as the other CS, respectively, in the associative, taxonomic, unrelated noun, and unrelated noun-nonnoun conditions (similarly, ROCK was used with HARD, HILL, MEAT, or MEET; and LION with ROAR, DEER, MAID, or MADE).

Subjects and Procedure. The subjects were $64 \mathrm{men}$ and 128 women from introductory psychology classes at the University of 'Wisconsin, 24 in each related-CS group and 12 per control group. All subjects received $40 \mathrm{CS}+$ and 40 CS - trials which were randomly interspersed, with the restrictions that no more than four trials of the same type occurred in succession and each 10-trial block contained five positive and five negative trials. Tape-recorded eyelid conditioning instructions simply informed the subjects that they would see and feel a series of stimuli, they were not to try to "figure out" the experiment, and they should neither aid nor inhibit their natural eyelid responses. To assess the perceived relatedness of the several pair types, afterward subjects were given a 9-point scale on which they rated all $15 \mathrm{CS}$ sets as to the degree to which the two words of each pair seemed to "go together" in some way.

\section{Results and Discussion}

A conditioned response (CR) was defined as any eyelid closure which occurred from $200 \mathrm{msec}$ after CS onset to the time of US onset. Subjects were classified on the basis of their response form as conditioners (Cs) with typically gradual onset, small magnitude CRs, or voluntary-form responders (Vs), with rapid and complete anticipatory closures, using the objective first derivative criterion of Hartman and Ross (1961). Of the 192 subjects, 94 were classified as Cs and 98 as Vs, distributed roughly equally in the 10 groups.

The major conditioning indexes examined were terminal (final 30 trials) percentage response to the reinforced word (CR+), response to the nonreinforced word (CR-), and discrimination between the CS+ and CS-. The latter measure, presented in the upper part of Table 1, was computed by subtracting mean percentage $\mathrm{CR}$ - from mean percentage $\mathrm{CR}+$ during the last 30 conditioning trials. A three-way unweighted means analysis of variance performed on each of the conditioning measures revealed no reliable relatedness or ISI effects. The only significant effect was a generally higher response level by Vs than by Cs to both the CS+, $\mathrm{F}(1,172)=24.98, \mathrm{p}<.0001, \mathrm{MS}_{\mathrm{e}}=787.30$, and $\mathrm{CS}-$, $\mathrm{F}(1,172)=10.90, \mathrm{p}<.002, \mathrm{MS}_{\mathrm{e}}=987.24, \mathrm{a}$ finding typical of conditioning work with human subjects (e.g., Cerekwicki et al., 1968).

In view of the specific interference predictions made, however, selected t tests (two-tailed) were also carried out comparing related CS and appropriate control conditions within the different topography-ISI combinations. No relatedness differences were found for terminal discrimination or CR- level, but Vs gave significantly more CS+ responses for homonyms than for unrelated noun-nonnoun discriminanda at the $1400-\mathrm{msec}$ ISI, $\mathrm{t}(172)=2.01, \mathrm{p}<.05$. In contrast, Cs at the long ISI tended to give fewer positive responses to homonyms than to control CSs, $t(172)=1.69$, $p<.10$. These data suggest that at least relatedness of a homonymic type may begin to affect conditioned excitation at an extended ISI, but that the direction of this effect will be related to the subject's response topography.

The extent of difference between the two control conditions was also explored by t tests which compared the unrelated noun-noun and noun-nonnoun conditions within each ISI-topography combination. Terminal discrimination and CR - level were generally similar for the two control conditions. However, the CR+ level or $\mathrm{V}$ - and C-form responders was differentially affected at the $1400-\mathrm{msec}$ ISI, in that noun-noun stimulus sets resulted in more $\mathrm{CS}+$ responding than noun-nonnoun sets by Vs, $\mathrm{t}(172)=1.98, \mathrm{p}<.05$, but less $\mathrm{CS}+$ responding by $\mathrm{Cs}$ there, $\mathrm{t}(172)=2.17, \mathrm{p}<.05$.

The questionnaire rating data proved to be very similar across all conditions. Overall, there was little difference between the taxonomic and homonymic word types, which were both intermediate in perceived relatedness $(\mathrm{Ms}=6.0$ and 5.4$)$, while associates were consistently rated as very highly related $(M=8.0)$ and control words as very little related $(M=1.8)$. In particular, then, while associates were considered by subjects to be highly related and neutral words very unrelated, conditioned discrimination was nonetheless comparable for these two types of CS sets. 
Table 1

Mean Percentage Terminal Discrimination as a Function of Interstimulus Interval, Response Topography, and Relatedness Between the CS+ and CS-

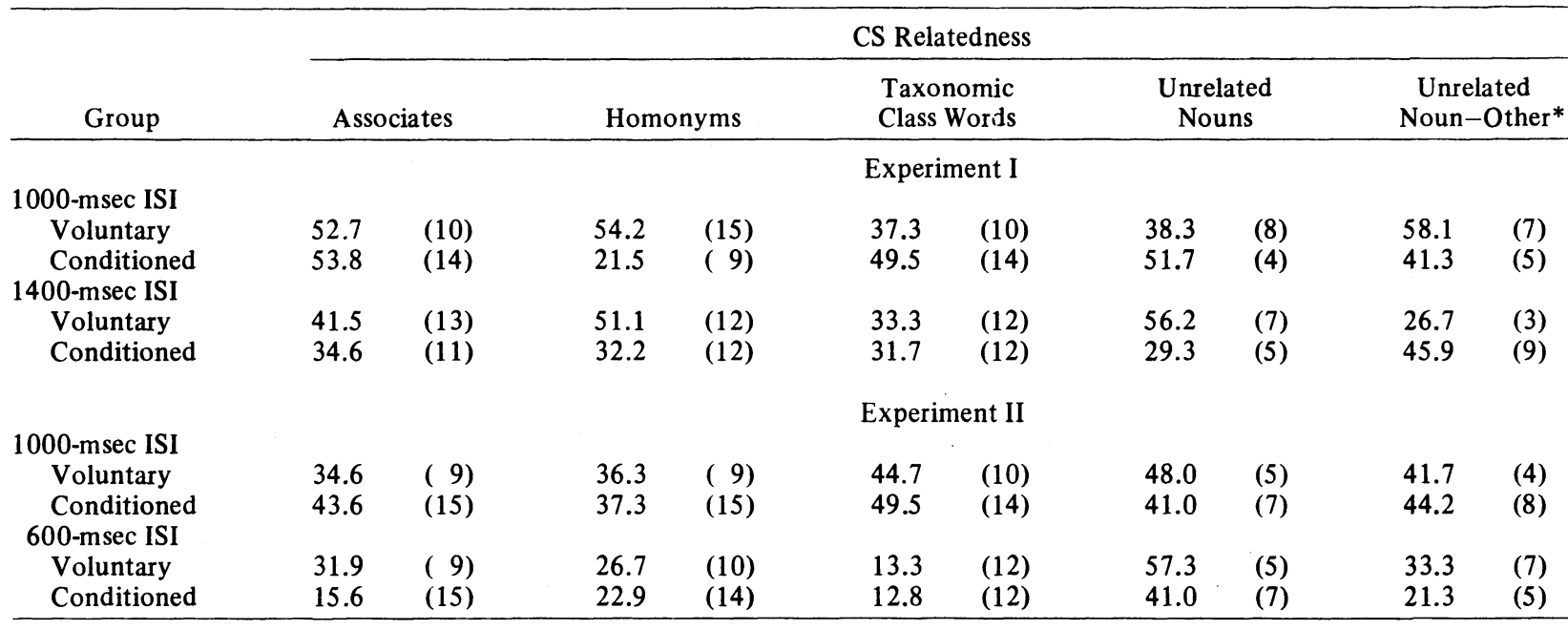

Note-Numbers in parentheses indicate the group ns. Terminal discrimination scores were obtained by subtracting mean percentage response to the CS-from mean response to the CS+during the final 30 conditioning trials.

*One CS was a noun and the other CS a verb or adjective.

\section{EXPERIMENT II}

In view of the basically negative relatedness results in Experiment I, all of the 1000 -msec ISI conditions were replicated in a second experiment, which also further explored the relatedness variable by examining its influence at the short end of the ISI range normally used in differential conditioning. Thus, the five types of relatedness were tested at a $600-\mathrm{msec}$ ISI as well as at the $1000-\mathrm{msec}$ interval. In particular, if associative relatedness interferes with VDL only at fast presentation rates, as McCarthy (1973) suggests, then such relatedness may similarly have a detrimental effect upon conditioned discrimination only when a very brief ISI is employed.

\section{Method}

Experimental Design. The design was identical to the 5 by 2 factorial design employed in Experiment I, with the exception that a short ISI value of $600 \mathrm{msec}$ was used in place of the $1400-\mathrm{msec}$ value. Thus, there were five types of CS relatedness (associative, homonymic, taxonomic, unrelated nouns, and unrelated noun-nonnoun stimuli) examined at two levels of ISI (600 and $1000 \mathrm{msec}$ ).

Apparatus, Materials, Procedure, and Subjects. The equipment, stimuli, and procedure were the same as those used in the first experiment. For the $600-\mathrm{msec}$ ISI conditions, the CS duration was $800 \mathrm{msec}$, and US onset occurred $600 \mathrm{msec}$ after CS+ onset. The subjects were 64 men and 128 women from introductory psychology classes.

\section{Results and Discussion}

As in Experiment I, subjects were divided into Vs and Cs on the basis of CR form. Of the 192 subjects, 110 were Cs and $82 \mathrm{Vs}$, distributed relatively equally among the 10 groups. The same three conditioning measures were examined as before, i.e., percentage $\mathrm{CR}+, \mathrm{CR}-$, and discrimination between the CS+ and CS-during the final 30 conditioning trials (the latter measure is presented in the bottom part of Table 1). A three-way unweighted means analysis of variance on each of these indexes revealed that terminal discrimination was significantly influenced only by ISI, with poorer differentiation at the $600-\mathrm{msec}$ than at the $1000-\mathrm{msec}$ interval, $\mathrm{F}(1,172)=9.29, \mathrm{p}<.005, \mathrm{MS}_{\mathrm{e}}=934.23$, while Vs again showed a generally higher response level than Cs to both the CS+, $\mathrm{F}(1,172)=10.45, \mathrm{p}<.002$, $\mathrm{MS}_{\mathrm{e}}=760.20$, and the CS-, $\mathrm{F}(1,172)=4.79, \mathrm{p}<.03$, $\mathrm{MS}_{\mathrm{e}}=848.79$. The ISI variable was also significant in the $\mathrm{CR}$ - but not the CR+ analysis, $\mathrm{F}(1,172)=3.83$, $\mathrm{p}<.05$, which suggests that the adverse effect of the shortened ISI upon discrimination was primarily a consequence of increased responding to the CS- (cf. Hartman \& Grant, 1962).

Individual $\mathrm{t}$ tests comparing related-CS and control conditions within the different topography and ISI combinations again indicated no differences at the 1000msec ISI. At the 600-msec ISI, however, Vs discriminated unrelated noun-noun sets better than taxonomically related CSs, $\mathrm{t}(172)=2.91, \mathrm{p}<.05$, with a similar trend shown by $\mathrm{Cs}$ as well, $\mathrm{t}(172)=1.86$, $\mathrm{p}<.10$. The inferiority of taxonomic discriminanda tended to be due largely to depressed CS+ responding for Cs, $t(172)=1.91, p<.10$, but elevated CSresponse for Vs, $\mathrm{t}(172)=1.82, \mathrm{p}<.10$. These data thus suggest that relatedness may produce some interference with discrimination at a short ISI, but that this is weak in nature and limited to conceptual or semantic similarity. The results further suggest that the locus of 
such interference may be related to CR topography, with a tendency for $\mathrm{Cs}$ to inhibit response to the taxonomic CS+ word, while Vs instead generalize excitation to the taxonomic CS- word.

Comparisons of the two unrelated-word control conditions by $\mathrm{t}$ tests indicated no significant differences. Finally, the questionnaire results were very similar to those of the first study. As before, degree of relatedness of CS+, CS - pairs tended to be rated similarly regardless of the subject's treatment group or response topography, with overall means of 8.0, 6.0, 5.8, and 1.8 for associates, homonyms, taxonomic class words, and unrelated words, respectively.

\section{GENERAL DISCUSSION}

Neither frequency theory nor the feature analysis models were found to have clear predictive validity for the present differential conditioning situation. The frequency theory prediction that associates should be more difficult to discriminate than unrelated words was not supported by either experiment, even when a very short ISI of $600 \mathrm{msec}$ was employed. In this respect, the present data agree with much VDL research (see Eckert \& Kanak, 1974). On the other hand, while the taxonomic relatedness effects at the short ISI agree with feature analysis expectations, the lack of homonymic interference conflicts with both feature analysis predictions and VDL data (see Eckert \& Kanak, 1974).

It may be that while sensory and semantic feature overlap have a similar detrimental effect on VDL, in the conditioning situation involving the nonoptimal short ISI, semantic CS features are weighted more heavily than sensory ones, or perhaps encoded prior to them [although this would conflict with Shulman's (1970) time-dependent encoding principle], and hence semantic, but not sensory, feature overlap acts to interfere with conditioned discrimination. Under more optimal circumstances (1000-msec ISI), however, the conditioning contingencies appear to take priority over any cognitive awareness of relatedness (evident in the questionnaire data), even though subjects are in a relatively unmobilized and passive state. Thus, even highly similar discriminanda appear to be readily encoded there so as to allow effective differential conditioning, either through mechanisms which suppress encoding of overlapping features, or which in fact use these features in tagging the CS+ and CS- differentially (cf. Kausler, 1974b).

While no clear differences emerged between the two unrelated-word control groups, these conditions were not specifically designed to assess imagery or grammatical class effects, but only to provide a control for these factors.
Particularly in view of the fact that at least one CS was always a noun and hence the control stimulus sets differed only minimally, the lack of difference is not surprising. Even so, the sizeable performance differences between the two control conditions in a number of instances indicate the importance of providing appropriate imaginal and syntactic control comparisons in conditioning work with verbal stimuli.

\section{REFERENCE NOTE}

1. Perry, L. C., Grant, D. A., \& Schwartz, M. Differential eyelid conditioning with grammaticality of a noun phrase as the discriminandum. Paper presented at the meeting of the Psychonomic Society, St. Louis, 1971.

\section{REFERENCES}

Cerekwicki, L. E., Grant, D. A., \& Porter, E. C. The effect of number and relatedness of verbal discriminanda upon differential eyelid conditioning. Journal of Verbal Learning and Verbal Behavior, 1968, 7, 847-853.

Cohen, B. H., Bousfield, W. A., \& Whitmarsh, G. A. Cultural norms of verbal items in 43 categories. Technical Report No. 22, University of Connecticut, 1957.

ECKERT, E., \& KANAK, N. J. Verbal discrimination learning: A review of the acquisition, transfer, and retention literature through 1972. Psychological Bulletin, 1974, 81, 582-607.

Ekstrand, B. R., Wallace, W. P., \& Underwood, B. J. A frequency theory of verbal-discrimination learning. Psychological Review, 1966, 73, 566-578.

Hartman, T. F., \& Grant, D. A. Differential eyelid conditioning as a function of the CS-UCS interval. Journal of Experimental Psychology, 1962, 64, 131-136.

Hartman, T. F., \& Ross, L. E. An alternative criterion for the elimination of "voluntary" responses in eyelid conditioning. Journal of Experimental Psychology, 1961, 61, 334-338.

KAUSLER, D. H. Continuity of processes across variants of recognition learning. In $R$. $L$. Solso (Ed.), Theories of cognitive psychology: The Loyola symposium. Potomac: Erlbaum, 1974. (a)

KAusler, D. H. Psychology of verbal learning and memory. New York: Academic Press, 1974. (b)

McCARThY, S. V. Verbal discrimination learning as a function of associative strength between noun pair members. Journal of Experimental Psychology, 1973, 97, 270-271.

Shapiro, S. I., \& Palermo, D. S. An atlas of normative free association data. Psychonomic Monograph Supplements, 1968, 2(12, Whole No. 28), 219-250.

Shulman, H. G. Encoding and retention of semantic and phonemic information in short-term memory. Journal of Verbal Learning and Verbal Behavior, 1970, 9, 499-508.

(Received for publication November 17, 1975.) 